\title{
EFFICIENT ION HEATING VIA FINITE-IARMOR-RADIUS ICRF
}

\author{
M. Ono, G. A. Wurden, ${ }^{\dagger}$ and K. L. Wong \\ Plasma Physics Laboratory, Princeton University \\ Princeton, New Jersey 08544 \\ March, 1983
}

ABSTRACT

Ion heating by externally launched ion Bernstein waves is investigated in the ACT-1 hydrogen plasma. Detailed measurements of wave absorption and of the ion temperature profiles have clearly identified various heating layers near the ion-cyclotron harmonics of deuteriumize and tritiumlike ions. The observed heating of $10 \mathrm{eV} / \mathrm{WATT} / 10^{10} \mathrm{~cm}^{-3}$ and the power-balance estimates suggest excellent overall efficiency for FLR-ICRF heating.

\section{DISCLAIMER}

This report was prepared as an account of work sponsored by an agency of the United Stutes Government. Neither the United Statcs Gowerament nor any agency thereof, nor any of their employoes, mates any warranty, express of implied, or asqumes any legal liability or responsibility for the accuracy, completenese, or usefulness of any information, apparatus, produch, or process disclosed, or represents that its use would not inlringe privately owned rights. Refer* ence berein to any specific commercial ptoluct, procest, or serviot by trade anme, trademark, manufacturer, or olberwive doce not necentarily constitute or imply its endorsement, necommendation, of Psvoring by the United Stales Government or any agency thereof. The viem and opinions of authors expresecs bertip do not necessurily state of reflect those of the United States Govemment or any agency thereof.

\footnotetext{
${ }^{\dagger}$ present address: Los Alamos National Laboratory, Los Alamos, NM 87545 .
} 
Until now, radio frequency (rf) heating schemes have utilized cola plasma waves to carry the rf power into the plasma interior. Propagation of these modes is not critically influenced by the plasma temperature, and the cold modes have provided rich opportunities for successful vave physics investigations in research plasmas which are often cold and collisional. An entirely new heating possibility arises for hot collisionless reactor-grade plasmas, where a full finite-Larmorradius (FLR) ICRF wave ${ }^{1-3}$ can be utilized to carry rf power deep into the plasma interior. FLR-ICRF wave heating would have several important technological advantages for reactor-plasma heating. 4 In physics terms, this mothod of plasma heating differs from the conventional schemes in that the wave power is mainly carried by acousticlike particle motion instead of by the Poynting flux. Reported here is the first experimental observation of FLR-iCRF heating. The apparatus used is the ACT-3. toroidal device with externally launched ion Bernstein waves (IBW). Hydrogen ions initially at $T_{i} \sim 1.5 \mathrm{eV}$ are heated to $\sim 50 \mathrm{eV}$ with an efficiency of $\Delta \mathrm{T}_{i} / \mathrm{P}_{\mathrm{rf}} \mathrm{n}_{0}=10 \mathrm{eV} / \mathrm{WATT} / 10^{10} \mathrm{~cm}^{-3}$. Applying the FLR-ICRF concept to the heating of a toroidal device such as a tokamak, ion Bernstein waves are launched from the low field side of the torus toward the ion oyclotron harmonic resonance layer, the latter being located in the higher field piasma interior as shown by Figs. $1(a)$ and (b). Jue to the increasing $B_{0}$ (or decreasing $\left.\omega_{i}^{\prime} \Omega_{i}\right), k_{\perp} o_{i}$ increases, 
and when $B_{0}$ increases sufficiently to satisfy the wave resonance condition $\left(\omega-m \Omega_{j}\right) /\left(k_{n} v_{j}\right) \leq 3, v_{j}{ }^{2} \equiv 2 T_{j} / m_{j}$, ion cyclotron harmonic absorption takes place with a damping rate $\operatorname{Im} k_{x}=\operatorname{Im} k_{x x^{\prime}} /\left(\partial K_{x x^{\prime}} / \partial K_{1}\right)$ given by

$$
\operatorname{Im} k_{1} \simeq k_{1} \frac{\sqrt{\pi} \omega_{p j}^{2} m^{2} Q_{m}\left(\lambda_{j}\right)}{\left|k_{1} \partial k_{x x} / \partial k_{1}\right| \omega k_{n} v_{j}} \exp \left[-\left(\frac{\omega-m \Omega j}{k_{n} v_{j}}{ }^{2}\right]\right.
$$

where $Q_{m}\left(\lambda_{j}\right) \equiv I_{m}\left(\lambda_{j}\right) \exp \left(-\lambda_{j}\right) / \lambda_{j}, I_{m}\left(\lambda_{j}\right)$ is the modified Bessel function of argument $\lambda_{j} \equiv k_{\perp}{ }^{2} \mathrm{~T}_{i} / \mathrm{M}_{j} \Omega_{j}{ }^{2}, \mathrm{~m}$ is the harmonic number and $j$ denotes the resonant ion species. The term $\mathrm{Q}_{m}\left(\lambda_{j}\right) \simeq\left(\lambda_{j} / 2\right)^{\mathrm{m}-1} / \pi$ ! increases rapidly with $\lambda_{j}$, so that ion Bernstein waves with $\lambda_{j}=\theta(\mathrm{L})$ can interact with ion cyclotron harmonic resonances for $m \leq 7$ and, thus, can be used to heat ions even at relatively hjgh harmonic cyclotror frequencies.

Experiments were carried out in the $5 \mathrm{~kg}$ field of the ACT-1 toroidal device. 5 : schematic plan of the experimental setup is shown in Fig. I(b). A hydrogen plasma is created by a hot tungsten filarient source operating with a neutral pressure of $1.7 \times 10^{-5}$ Torr and producing a low collision, warm ion plasma $\left[\omega=2 \Omega_{i}: 10^{8} \gg v_{i j}, v_{i 0} \leq 20^{4}\right.$ ] with $T_{e}=2.5 \mathrm{ev}, \mathrm{T}_{i}=$ $1.5 \mathrm{ev}$, and $\mathrm{n}_{0} \leqslant 10^{11} \mathrm{~cm}^{-3}$. To preserve the Maxwellian nature of the clasma and to minimize electron Landau damping, the high energy ionizing electrons $(\varepsilon \leq 150 \mathrm{eV})$ are carefully kept out of the experimental region. Waves are detected by rf probes (configured as shown in Fig. 1 (b) to minimize the probe shadow effect ${ }^{6}$ ) and by a $\mathrm{CO}_{2}$-laser scattering apparatus. ${ }^{6}$ At the same 
time, the bydrogen ion temperature is monitored by the newly developed IBW $T_{i}$ diagnostic technigue which utilizes the measured wave dispersion characteristics of a lower power IBW test wave. ${ }^{6,7}$ A high-frequency lock-in amplifier (PAR 5202) has been used to detect selectively the tost wave in the presence of higher power heating waves. With alternately phased electrostatic antennas, $70 \%$ of the applied rf power is coupled to the plasma in the form of inward propagating ion Bernstein waves.

The Iinear wave physics, mode-transformation process, propagation, dispersion relation, etc., have already been described $6-8$ in detail for this case of ion Bernstein wave launching. Wave absorption layers are providen by the ion cyclctron harmonj.c resonances of the naturally occurring hydrogen molecular ions $\mathrm{H}_{2}{ }^{+}$and $\mathrm{H}_{3}{ }^{+}$(concentrations $20-25 \%$, denoted here as $\mathrm{D}$ and T) which, from a wave physics point of view, behave identically to deuterium and tritium ions, respectively. ${ }^{7,8}$ The measured wave dispersion relation near the fifth barmonic resonance of $\mathrm{H}_{3}{ }^{+}$ has been plotted in the solid triangles in Fig. I(a). Strong IBW absorption, observed near the resonance layer, can be seen in the measurca radial wave packet amplitude profiles shown, in Fig. I(c), at several wave frequencies. The cashed curve indicates the position of the center of the resonance layer. Due to the simple toroidal magnetic field geometry of ACT-1, 5 the heating layer (constant $B_{0}$ surface) coincides with the ion 
drift surface, a circumstance which greatly simplifies the heating layer identification. Figure $2(a)$ shows measured ion temperature profiles for various rf power levels. The ion temperature undergoes a nearly thirty fold increase from its $1.5 \mathrm{eV}$ unheated value (appiied rf power of $10 \mathrm{~W}$ at $\left.n_{0} \approx 2.5 \times 10^{10} \mathrm{~cm}^{-3}\right)$. The position of the ion temperature peak coincides well with the observed region of strong wave absorption. In Fig. $2(i)$, the observed peak ion temperature is plotted as a function of applied rf power. The heating efficiency is $\Delta \mathrm{T}_{\mathrm{i}} / \mathrm{P}_{\mathrm{rf}} / \mathrm{n}_{\mathrm{o}} \cong 10 \mathrm{eV} / \mathrm{WATT} / 10^{10} \mathrm{~cm}^{-3}$. The present FLRICRF heating has an interesting power scaling in that with in: creasing $r$ power, the higher $T_{i}$, longer $\lambda_{1}$, faster $v_{p h}$ and $v_{g}$ ' and lower collision Erequency $\gamma_{i}$ will all contribute to improved wave penetration.

The measured ion energy increase, $\Delta\left(n T_{i}\right)$, is plotted in Fig. 3 as a furction of radius for the $10 \mathrm{~W}$ case. Also in this figure, the shaded area portrays the power deposition predicted by a detailed ray cracing calculation. The calculation indicates that Doppler shift will cause the wave absorption to take place in front of the resonance layer $\left(\omega \simeq 5.1 \Omega_{T}\right)$ and this prediction is in excellent agreement with the experimental observation.

An estimate of power balance can be made from a comparison of the observed ion energy confinement time, obtained from the 
measured ion energy increase per unit rf power, with the expected losses due to neutral cooling and ion drift. In an insert within Fig. 3, the neutral cooling loss, the ion dxift loss, and the combined total loss are plotted as functions of ion temperature. Also shown in the insert is the observed loss rate based on the measured ion energy increase. These comparisons support the conclusion that the overall FLR-ICRF heating efficiency is excellent even in the relatively low temperature ACT-1 plasma.

Various heating layers can be readily identified by scanning the heating wave frequency while monitoring the ion temperature at a given radial position, keeping other wave and plasma parameters constant. Two strong heating layers with comparable heating efficiencies of $10 \mathrm{eV} / \mathrm{WATT} / 10^{10} \mathrm{~cm}^{-3}$ are observed near $5 \Omega_{\mathrm{T}}$ [Fig. $4(\mathrm{a})$ ] and $5 \Omega_{\mathrm{D}}$ [Fig. 4(b)]. A partial absorption layer resonance can also be seen in Fig. 4 (b) at $8 \Omega_{\mathrm{T}}$. A heating layer at $7 \varsigma_{\mathrm{T}}$ with a somewhat smaller heating efficiency of $\Delta \mathrm{T}_{i} / \mathrm{P}_{\mathrm{Yf}} / \mathrm{n}_{\mathrm{O}}=7 \mathrm{eV} /$ WATT $/ 10^{10} \mathrm{~cm}^{-3}$ has also been seen. These heating efficiencies are maintained up to the maximum flasma density, $\pi_{0} \simeq 10^{11} \mathrm{~cm}^{-3}$, obtainable in our low pressure filament discharge. This experiment has seen no significant deleterious effects associated with high power rf except when the ions are heated above $50 \mathrm{eV}$; here the particle losses in ACT-I become significant and prevent meaningful heating studies. 
In conclusion, efficient ion heating by FLR-ICRF has been observed for the first time in the ACT-1 toroidal device. Detailed measurements on wave absorption and ion temperature profile have clearly identified strong heating layers near the fifth harmonics of deuteriumlike and tritiumlike ions. The observed heating is consistent with a calculation based on the ion cyclotron harmonic damping. From power balance estimates, nearly all of the applied rf power can be accounted for by the observed ion energy increase, indicating excellent overall efficiency of the present heating process.

Although FLR-ICRF heating should work most favorably in high temperature, high field, reactor-grade plasmas, the present $A C T-1$ heating result and further theoretical investigations $4,9,10$ suggest that a timely experiment could be performed on existing medium-size tokamaks $(R \geqslant 100 \mathrm{~cm}$ ) with relatively high magnetic fields $\left(B_{0} \geq 15 \mathrm{kG}\right)$. It is also worth noting that the present experimental observation may be relevant for ongoing tandem mirror ${ }^{11}$ and $\mathrm{EBT}^{12}$ TCRF heating experiments where anomalous ion heating has been reported at relatively high ion cyclotron harmonic frequencies $(m \geqslant 3)$, a result which is difficult to explaj.n solely in terms of fastwave damping.

\section{ACKNOWLEDGMENTS}

The authors would like to thank T. H. Stix for valuabie comments, and J. Taylor and $\mathrm{W}$. Kineyko for technical assistance. This work was supported by the U.S. DoE Contract No. DE-ACO2-76-CHO-3073. 
REFERENCES

${ }^{1}$ D. G. Swanson, Phys. Fluids $10,1331(196 \%)$.

${ }^{2}$ J. P. M. Schmitt, Phys. Rev. Lett. 31, 982 (1973).

${ }^{3}$ M. Ono and k. L. Wong, Phys. Rev. Lett. 45, 1105 (1980).

${ }^{4} \mathrm{M}$. Onc et al., in Proceedirigs of the $2 \mathrm{nd}$ Joint Grenoble-Varenna International symposium of Heating in Toroidal Plasmas

(Commission of the European Communities, Directorate-Ceneral XII-Fusion Programme, Brussels, 1980), Vol. I, P. 593.

${ }^{5}$. I. Wong, M. Ono, and G. A. Wurden, Rev. Sci. Instrum. 53 , $409(1982)$.

${ }^{6}$ G. A. Wurden, Ph.D, thesis, Princeton University, 1982 .

${ }^{7}$ G. A. Wurden, M. Ono, and K. L. Wong, Phys. Rev. A: 26, 2297 $(1982)$.

${ }^{8}$ M. Ono, K. L. Wong, and G. A. Wurden, Princeton Plasma Physics Laboratory Report No. PPPL-1905; 1982. (This also gives reference to earlier works.)

${ }^{9}$ M. Ono, Phys. Fluids 25, 990 (1982).

${ }^{10}$ M. Ono, Princeton Plasma Physics Laboratory Report No.PPPL-1900, 1982 .

${ }^{11}$ s. N. Galovato et al., Nucl. Fusion 22, 751. (1982). 
${ }^{12} \mathrm{~F}$. W. Baity et al., in Proceedings of the $3 \mathrm{rd}$ Joint Grenoble-Varenna International symposium of Heating in

Toroidal Plasmas ICommission of the European Communities

Directorate-General XII-Fusion Programme, Brussels, 1982)

Vol. I, p. 319 . 
FIGURE CAPTIONS

FIG. 1. (a) IBW dispersion relation near $5 \Omega_{T}$ resonance layer. Solid curve is theory and the solid triangles are experimental values $\mathrm{H}_{1}{ }^{+}: \mathrm{H}_{2}{ }^{+}: \mathrm{H}_{3}{ }^{+}=0.45: 0.25: 0.28$. (b) Experimental setup. The antenna is located at $\mathbf{r}=7.8 \mathrm{~cm} . \quad$ (c) Radial wave packet amplitude profiles at several frequencies. Dashed curve defines the $\omega=5 \Omega_{\mathrm{T}}$ layer.

FIG. 2. (a) Ion temperature profiles for various rf power levels (as labeled). (b) Peak ion temperature vs rf power. $f=11.6 \mathrm{MHz}, B_{0}=4.75 \mathrm{~kg}, \mathrm{n}_{0} \simeq 2.5 \% 10^{10} \mathrm{~cm}^{-3}$. Lower efficiency for $P_{\text {If }} \leqslant 2 \mathrm{~W}$ is due to the collisional absorption which causes partial absorption of IBW before it reaches the resonance layer.

FIG. 3. Radial profile of net ion energy increase and theoretical power deposition profile (shaded). Insert - the measured ion energy loss rate (circle) and the classical loss rate; cx-neutral cooling, $v_{D}$-ion drift, and total-cx + $v_{D}$ loss. $P_{\text {rf }}=10 \mathrm{~W}, \mathrm{f}=11.6 \mathrm{MHz}$, and $\mathrm{B}_{\mathrm{O}}=4.75 \mathrm{kG}$.

FIG. 4. Ion temperature vs If frequency (a) $\omega / \Omega_{\mathrm{H}}=1,6-1.9$. (b) $\omega / \Omega_{\mathrm{H}}=2.4-2.75 . \mathrm{P}_{x \mathrm{f}}=10 \mathrm{w}, \mathrm{r}=3 \mathrm{~cm}, \mathrm{~B}_{\mathrm{O}}=4.75 \mathrm{kC}$, and $\mathrm{n}_{0}=2.5 \times 10^{10} \mathrm{~cm}^{-3}$. 

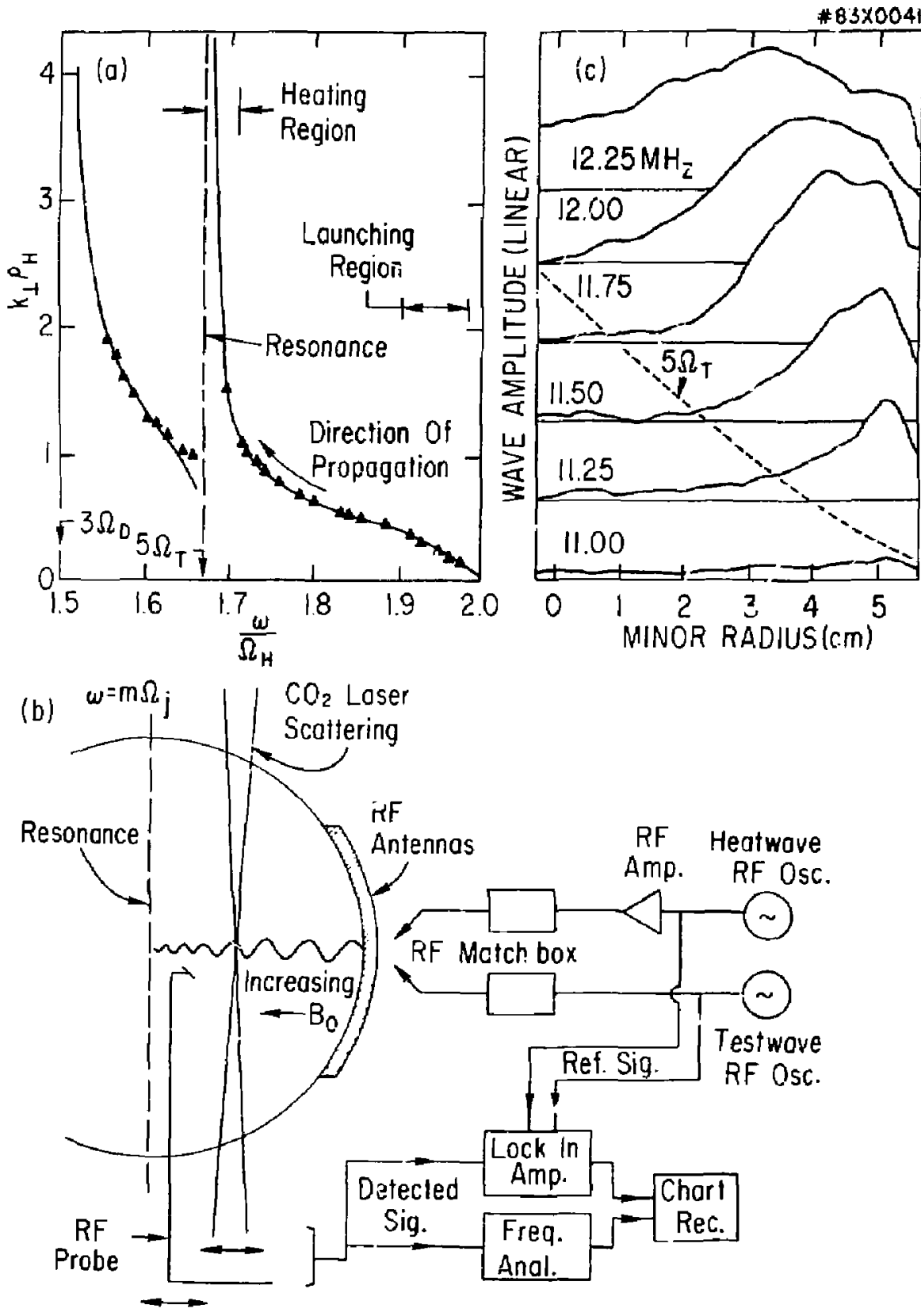

Fig. 1 

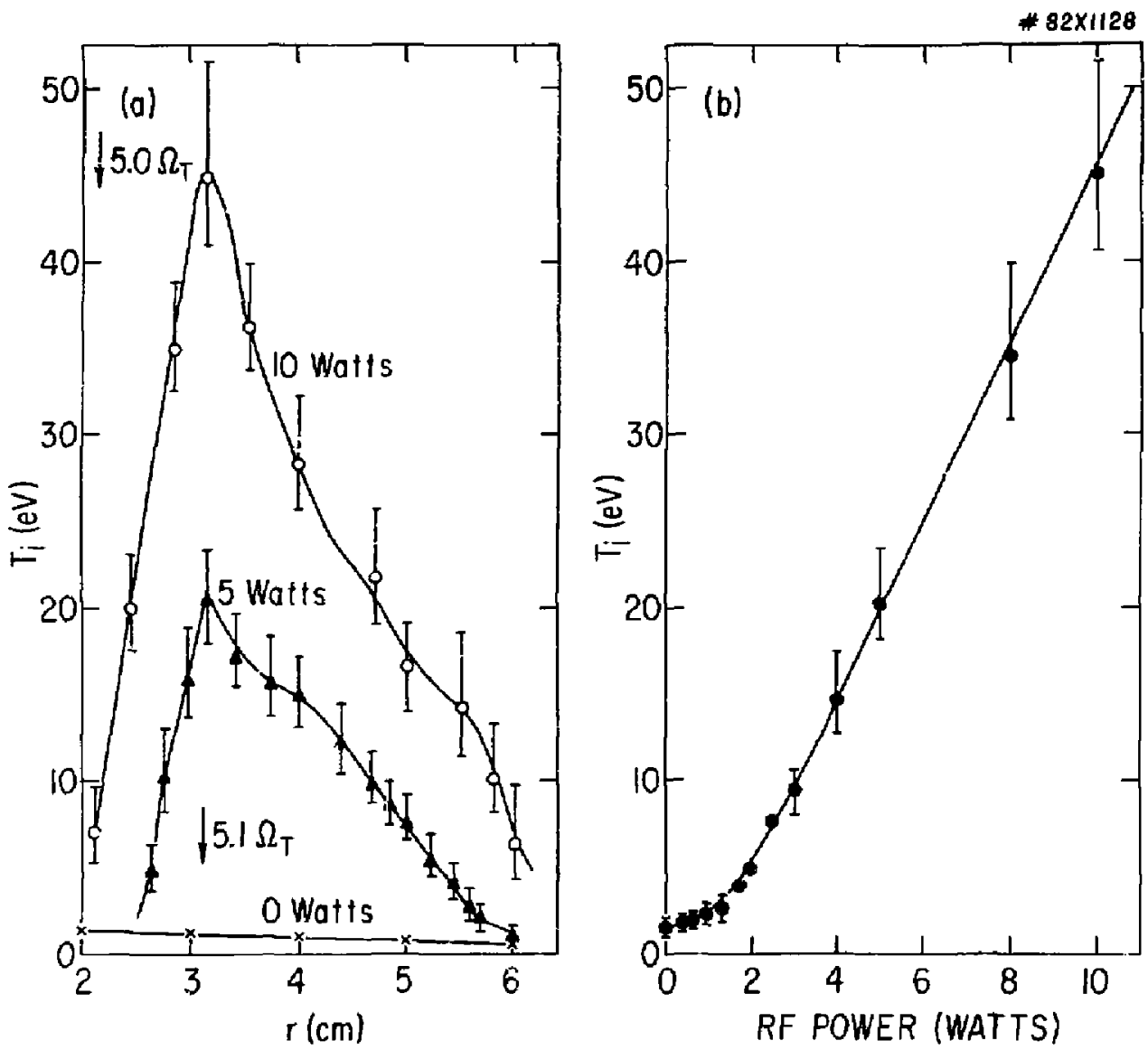

Fig. 2 


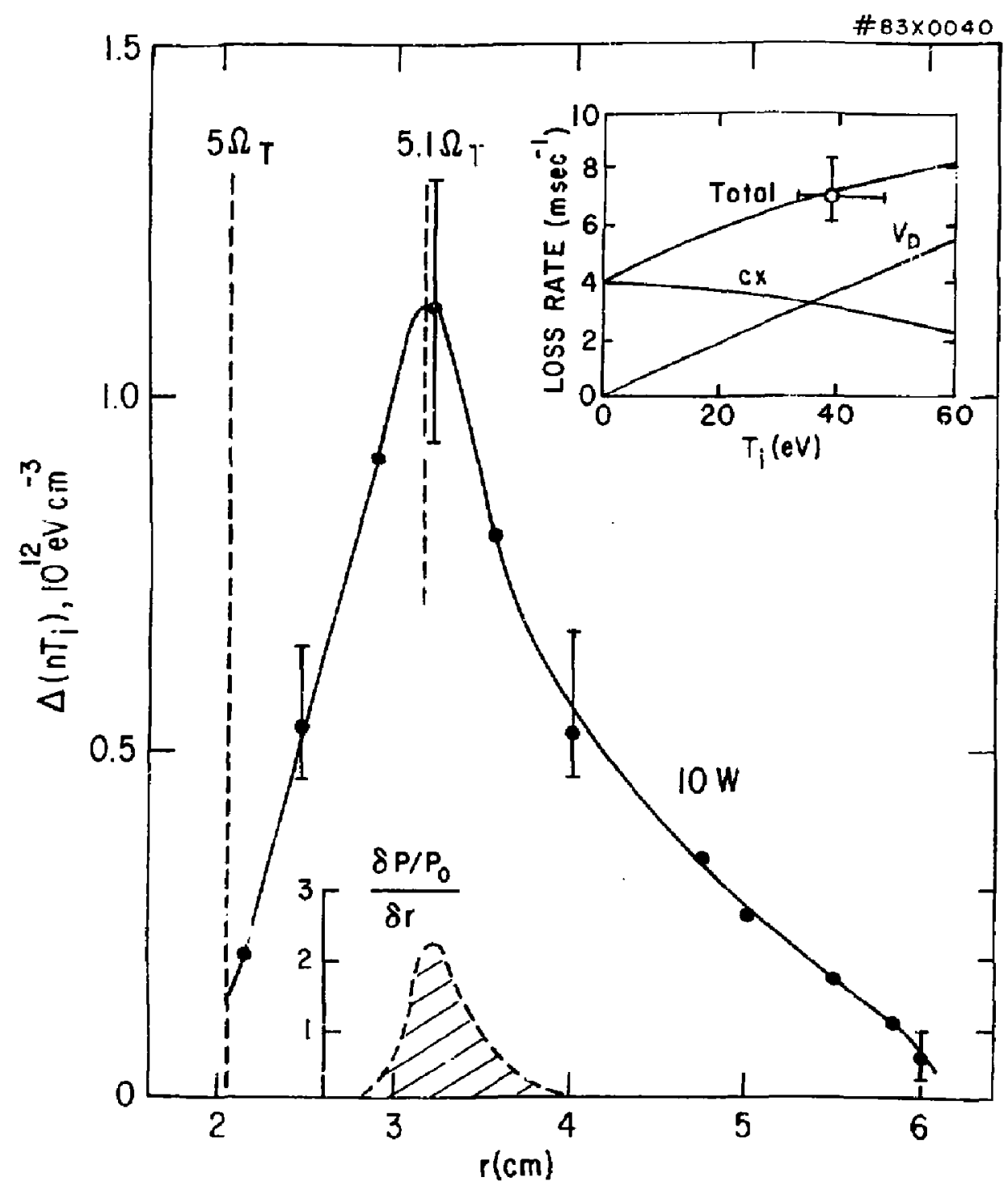

Fig. 3 

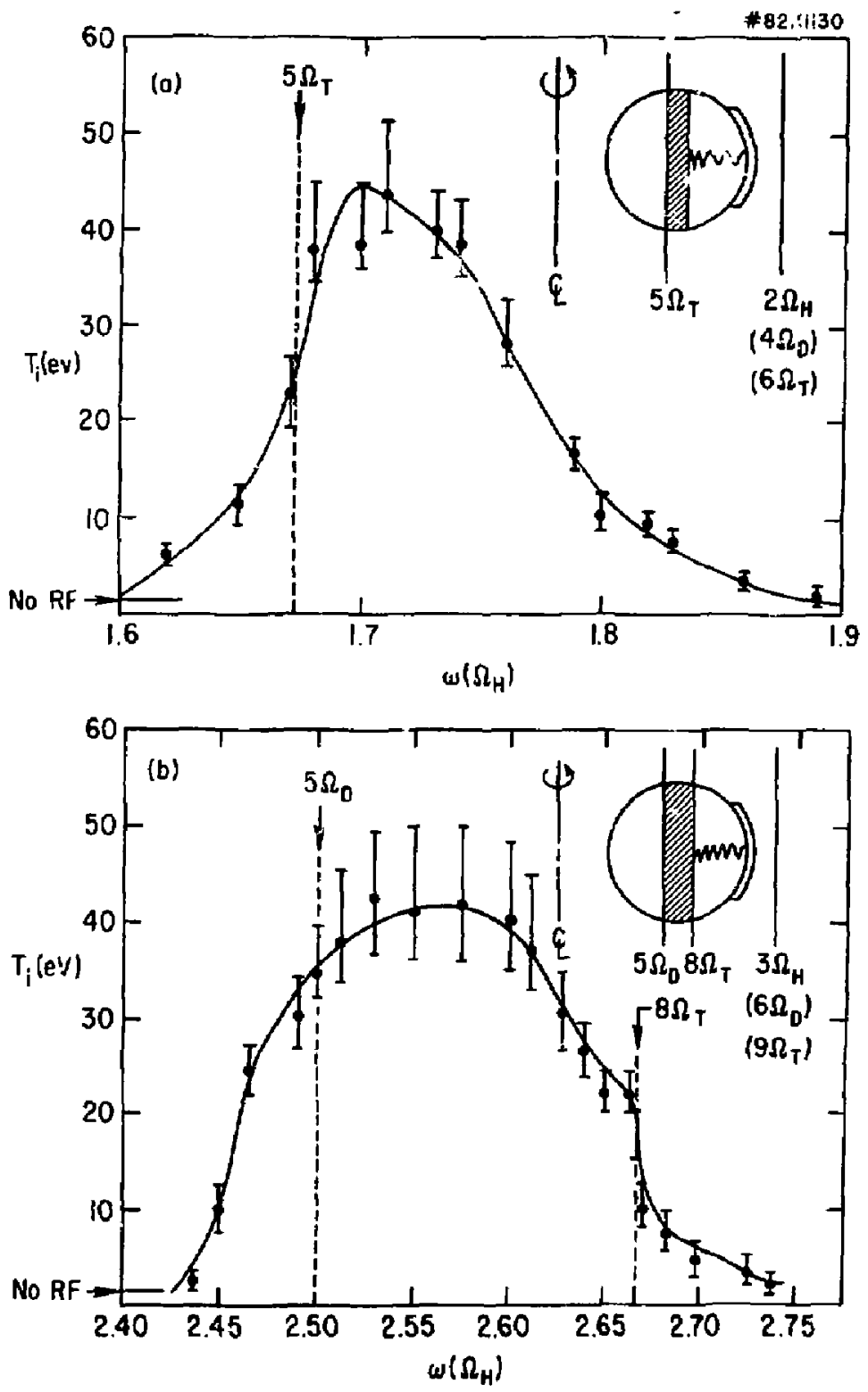

Fig. 4 


\section{EXTEFHNL DISTRIBUTION IN ADDITION TO TIC UC-2O}

Plasma Res hab, Austra Nat'I Univ, ALSTRalis

Dr. Frank J. Pagloni, Univ of wollongong, AUSTRR IA

Pror. I, A, Jones, filnders tin IV., ALSTRALIA

Frot. M.M. Brannan, Univ Syoney, AUSTRN IA

Prof. F. Cap. Inst Theo Fhys, ALSTRIA

Frot. Frork Yerheast, Inst theoretisehe, BELGILA

Dr. D. Palumbo, Do XII Fuslan Frog, BELGIUH

Ecole Roysle Mlultoira Lob de Phys Plamas, RElgilu

Dr, P.H. Sakanaka, UnIV Estadua I, ERAzIL

Dm. C.R. Jemes, Unlv of Alberta, CANAa

Prot. J. Telchmenn. Unir of Montreal, CAMADA

Dr. H. M. 5korsgard, UnIv of Saskatchewan, CANAOA

Prot. S.R, Sreenl wasan, University of Calcory, CANADh

Prot. Tuder W. Johnston, INRS-Energle, CANNA

Or. Hannes Bernard, UnIv British Columbla, Canapa

Or. M.P. Bachynskl, MPE Tochnologlos, Inc, CANMOA

Ztiongu LI, SH Inst Physles, CHIKh

Library. Tsing Hua Unlversity, CHIM

Librarlan, Institute of Physies, CHINA

Inst Plasmo Phys. ŞW Inst Physies, CHIMk

Dr. Potar lukee, Kombiskiha UnIv, GZECHOSLQYakIA

The LItrarian, Culnam Laboratory, ENGLAND

Prof. Schetzmen, Observotelre de NICe, FRAMCE

J. Rade', CEN-BP6, FRANCE

AM Oupes Llbrory, AH Dupas L lurary, FRANCE

Dr. TOm Must, Acodeny Elbllographic, hoNG kONG

Preprint Library, Cont Fies Inst Pnys, R:UNGaRy

Dr. A.K. Sundaram, Hhyslcal Research Lob, INDIA

Dr. 5.K. Trehan, Panjab UnI versity, INDIA

Dr. Indra, Mohon LaJ Das, Eonaras HInou Unjy, INDIA

Dr. L.K. Chavda, South Gujarat UnIv, Imola

Dr. R,K. CnhoJlani, Var Ruchl Mara, INDIA

B. But I, Physicol Raseareh Leb, Indis

Dr. Phlilip Rosenau, Isroel Inst Tach, I SRaEL

Prol. S. Cupermen, Tel Avty University, ISRAEL

Prot. G, Rostagn I, UnIV OI Padowe, ITALYY

Libra iar, int'l Ctr Theo Phys, ITALY

Mís Clello de Palo, ag soe EuRATOM-GNEN, ITALY

BIBIlotacs, dol OR ELRATOM, ITALY

Dr. H. Yamoto, Toshloa Res \& Dev, JAPAN

Prof. M. Yoshikaro, MAERI, Tokal Res Est, JAPAN

Prof. T. Uchlos, Unlversity of Takyo, JAPAN

Research into Conter, Nogoya Uniursity. JAPan

Prot. KYOJI Nishikeso, UnIV of HI roshims, JAPAN

SIgerc MOFI, MERI, JAPAN

Library, Kyoto Unlversity, AAPAN

Prof. I chlro Karakaml, NI mon UnIr, JAFXN

Prot. 5otoshl 1toh, Krushu University, LAPAN

Tech Into Ulvision, Kores Atoml i Energy. KOREA

Dr. R. Englend, Cludad Unlversitarla, mexico

Bibliothede, Fon-Inst Voor Plasma, NeTHERLwos

Prot. B.S. Liler, Unlvarsity of Wolketo, NEW ZENLANO
Dr. Surash C. Sharme, Unly af Calobar, NIGERIA

Prot. J,A,C, Cabrol, Inst Superlor Tech, PORTuGal

Dr. Oetevison Potrus, ALI CUZh University, RomaNiA

Dr. R. Jones, Not'l Univ 51 ingopore. SI Heapore

Frof. MaA. Hellbarg, Univers lty of Natal, SO AfRICA

Or. Johan de Villlers, Atonle Energr BC, SO AFRiCA.

Dr. J.A. Tugle, JEN, SPAIN

Prot. Hans wl thet mon, Chal mars Unis Tech, SWEDEN

Dr. Lennart Stenflo, Unlverslty of UMEA, SWEDEN

Librory, Roval Inst Tech, SIEDEN

Dr. ErIk T. Karlson, Uppsalo Unlversltet, SWEOEN

Cuntro de Recherchasen, Esole Polytech Fod, SwITZERLAND

Dr. Wol. Holses Nat'l Bur Stand, USA

Dr. W.M. Stocey, Gtorg Inst Tech, USA

Dr: S, T, Wu, Unlv Alabene, USA

Mr. Norman L, Oleson, UnIv S Flor Ida, USA

Dr. Benjonin Ma, Iowe State Unly, USA

Mogne Kristlanson, Texas Iech UrIr, USA

Dr. Raymond Askw, Auburn Unlv, USA

Dr. V.T. Tolok, Nharkov Phys Toch Ins, USSR

Dr. D.D. Ryutor, SI Der?on Aceo Scl, USSR

Dr. M.S. Rabinovich, Labadar Prysical Inst, USSR

Dr. G, A. Elliseow, Kurchetov Instiftute, USER

Dr. V.A. G lukhikh, Inst Electro-Physlea I, LSSR

Prat. T.J. Boyd, Univ College N wo les, waLeS

Dr. K. Schindier, Ruhr Unlversilat, W. Gepmanr

Nuelear Ras Esteb, Jullct Ltd, W. GERMuNY

LIbrarlan, Maxplanck Institut, W. GeRuwr

Dr. H.J. Koepplar, Un iversity Stuttgart, W. GEAMANY

Blbllothek, Inst Plasmetorschung, W. GePaMnY 